\title{
Trends and factors related to adolescent pregnancies: an incidence trend and conditional inference trees analysis of northern Nicaragua demographic surveillance data
}

\author{
Wilton Pérez ${ }^{1,2^{*}}$, Katarina Ekholm Selling ${ }^{1}$, Elmer Zelaya Blandón ${ }^{3,4}$, Rodolfo Peña ${ }^{1,5}$, Mariela Contreras ${ }^{1}$, \\ Lars-Åke Persson ${ }^{1,6}$, Oleg Sysoev ${ }^{7}$ and Carina Källestål ${ }^{8}$
}

\begin{abstract}
Background: We aimed to identify the 2001-2013 incidence trend, and characteristics associated with adolescent pregnancies reported by 20-24-year-old women.

Methods: A retrospective analysis of the Cuatro Santos Northern Nicaragua Health and Demographic Surveillance 2004-2014 data on women aged 15-19 and 20-24. To calculate adolescent birth and pregnancy rates, we used the first live birth at ages 10-14 and 15-19years reported by women aged 15-19 and 20-24years, respectively, along with estimates of annual incidence rates reported by women aged 20-24years. We conducted conditional inference tree analyses using 52 variables to identify characteristics associated with adolescent pregnancies.

Results: The number of first live births reported by women aged 20-24years was 361 during the study period. Adolescent pregnancies and live births decreased from 2004 to 2009 and thereafter increased up to 2014. The adolescent pregnancy incidence (persons-years) trend dropped from 2001 (75.1 per 1000) to 2007 (27.2 per 1000), followed by a steep upward trend from 2007 to 2008 (19.1 per 1000) that increased in 2013 (26.5 per 1000). Associated factors with adolescent pregnancy were living in low-education households, where most adults in the household were working, and high proportion of adolescent pregnancies in the local community. Wealth was not linked to teenage pregnancies.
\end{abstract}

Conclusions: Interventions to prevent adolescent pregnancy are imperative and must bear into account the context that influences the culture of early motherhood and lead to socioeconomic and health gains in resource-poor settings.

Keywords: Adolescent pregnancies, Incidence trend, Adolescent birth rate, Adolescent pregnancy rate, Conditional inference trees, Data mining, Predictors

*Correspondence: wperezc2018@gmail.com; wperez@incap.int

${ }^{2}$ Institute of Nutrition of Central America and Panama (INCAP), Calzada

Roosevelt 6-25, Zona 11, Guatemala, Guatemala

Full list of author information is available at the end of the article

\section{Background}

Adolescent pregnancies may have adverse consequences for the mother as well as the baby. Teenage mothers may have to interrupt or limit their education with consequences for employment and future income [1]. They run a higher risk of obstetric complications, including preeclampsia, fetal growth restriction, and preterm birth

(c) The Author(s) 2021. Open Access This article is licensed under a Creative Commons Attribution 4.0 International License, which permits use, sharing, adaptation, distribution and reproduction in any medium or format, as long as you give appropriate credit to the original author(s) and the source, provide a link to the Creative Commons licence, and indicate if changes were made. The images or other third party material in this article are included in the article's Creative Commons licence, unless indicated otherwise in a credit line to the material. If material is not included in the article's Creative Commons licence and your intended use is not permitted by statutory regulation or exceeds the permitted use, you will need to obtain permission directly from the copyright holder. To view a copy of this licence, visit http://creativecommons.org/licenses/by/4.0/. The Creative Commons Public Domain Dedication waiver (http://creativeco mmons.org/publicdomain/zero/1.0/) applies to the data made available in this article, unless otherwise stated in a credit line to the data. 
due to biological immaturity [2,3]. The children may be disadvantaged at birth with increased risk for low birth weight and stunted linear growth. These children more often fail to complete secondary school [4]. In low- and middle- income countries, complications of adolescent pregnancy and childbirth are leading causes of death in this age group [5].

The 2030 Agenda for Sustainable Development Goals (SDGs) [6] and the United Nations Global Strategy for Women's, Children's, and Adolescents' Health [7] identified adolescent pregnancies as an appropriate indicator. The agreed SDG indicator is the adolescent birth rate (ABR), which is the number of births per 1000 women 10-14 and 15-19years of age, respectively. Besides the $\mathrm{ABR}$, adolescent pregnancy rates (APR) are also reported, including ongoing pregnancies, abortions, and stillbirths per 1000 women 15-19years of age. Commonly these indicators are calculated using data retrospectively reported by 15-19-year-old women. In their 2013 report, the United Nations Population Fund stated that retrospective data from 20 to 24-year-old women provide better estimates, as reports from 15 to 19-yearold women censor data from the younger women who still face the risk of pregnancy before they reach the age of 19 years [8].

The WHO statistics from 2018 [9] indicate that there are annually 12.8 million births to mothers aged 15-19 years, corresponding to 44 births per 1000 women in that age group. Globally, ABR varies with the highest rates in Sub-Saharan Africa and the lowest in Western Europe and Central Asia. The global median ABR has, as reported in 2012, declined by $40 \%$ since the 1990s [10]. Latin America and the Caribbean have, however, experienced the slowest decline of all regions in the world $[11,12]$. This lower decrease in ABR is notable since this region has had a substantial decline in overall fertility [13]. Central America has a majority of this region's highABR countries [11].

In a study with an ecologic design including 162 countries, adolescent pregnancies were negatively associated with national wealth (per capita gross domestic product or GDP) and expenditure on education as a percentage of GDP and positively linked to income inequality (Gini index) [10]. A systematic review focusing on lowand middle-income countries [14] reported associations between adolescent pregnancies, low educational levels, and insufficient access to contraception. Teenage pregnancies more regularly occur in settings where early marriage and early sexual debut are common, more frequently occurring in rural areas and among ethnic minority groups [14]. Educational level and household wealth have consistently been associated with adolescent pregnancies $[11,15,16]$. A systematic review focusing on adolescent pregnancies in Sub-Saharan Africa pointed at the importance of community and national contextual factors in addition to individual or household level factors behind adolescent pregnancies [17].

A technical consultation on adolescent pregnancies in Latin America [11] stressed that multi-layered factors contribute to the occurrence and distribution of early pregnancy. Such factors were limited information on sexual and reproductive health, restricted access to sexual and reproductive health services including effective contraception, sexual violence, and unfavorable gender norms. Importantly, the status of motherhood might be a pathway out of poverty that can lead to early marriage and greater acceptance of early pregnancies. For some, pregnancy may be unintended and unwanted, while for others, it implies adult status and upward social mobility [18].

Recently (2018), the Council of Ministers of Health of Central America and the Dominican Republic (COMISCA) approved the regional strategic plan for preventing pregnancy in adolescence for each country to contextually adapt and implement [19]. The plan called for strengthening of the health and educational systems, adolescent empowerment, policies against violence, health promotion, and evidence generation. Despite this, there is an urgent need of recent scientific assessment of adolescent pregnancies and related determinants in Central America.

Nicaragua has consistently reported high adolescent birth and pregnancy rates, although with a slow decline $[11,13]$. The 2019 PAHO report stated that ABR for 15-19-year-olds was 83.3 per 1000 women [20]. The Northern Nicaragua Health and Demographic Surveillance System (NN-HDSS) includes demographic and reproductive data as well as household and individual characteristics. The NN-HDSS may target either a whole population area or a representative sampling frame. The NN-HDSS starts with a population and household baseline census followed by regular updating rounds to collect vital event information (i.e., births, deaths, immigration, and outmigration) and health-relevant outcomes. By 2021, the number of HDSS [similar to our NN-HDSS] registered in the International Network for the Demographic Evaluation of Populations and their Health is 45 in 19 low- and middle-income countries where the national and subnational vital registration system generates unreliable population estimates [21,22]. The nature of data collection of the NN-HDSS is longitudinal These data enable studies of trends in the local area and allow for analyses of social, household, and individual characteristics associated with adolescent pregnancies.

Thus, this study aimed to analyze the trend (20012013) in the incidence of adolescent pregnancies in the 
Cuatro Santos area, northern Nicaragua, based on Health and Demographic Surveillance data and to identify characteristics associated with adolescent pregnancies reported by 20-24-year-old women.

\section{Methods}

\section{Study setting and population}

The Cuatro Santos area, in the northern part of the Chinandega region, Nicaragua, consists of four municipalities of similar population size, with a total of 25,893 inhabitants (2014). This area, $250 \mathrm{~km}$ northwest of the capital Managua, is a mountainous terrain bordering Honduras. The climate is predominantly dry, and the traditional source of income has been the cultivation of grains and raising livestock, now with an increasing number of small-scale enterprises. A significant proportion of the population has out-migrated due to economic reasons [23]. In terms of healthcare, the Cuatro Santos area has one larger health center per municipality and the nearest hospital is $130 \mathrm{~km}$ distant. The healthcare service has on average five physicians per 10,000 inhabitants. Skilled birth attendance is estimated at $91 \%$ and the under-five mortality rate dropped from 40 per 1000 to 20 per 1000 live births between 1990 and 2008 [24-26].

In 1998, local stakeholders in the Cuatro Santos area developed a long-term strategic plan to facilitate multidimensional development initiatives to break the cycles of poverty. Interventions included water and sanitation, house construction, microcredits, environmental protection, school breakfasts, technical training, university scholarships, home gardening, breastfeeding promotion, and maternity waiting homes [24]. During the last decade, the proportion of individuals in this region living in poverty was reduced from 79 to $47 \%$ [25]. Primary school enrolment increased from 70 to $98 \%$. Under-five mortality dropped from 50 per 1000 live births in 1990 to about 20 per 1000 in 2014 [24-26].

\section{Northern Nicaragua health and demographic surveillance system (NN-HDSS) and study design}

In 2004, a census in the whole Cuatro Santos population covered essential health and demographic information [24]. Surveys followed in 2007, 2009, and 2014 and unique identifiers of households and individuals linked the data. Demographic changes in the households, such as births, deaths, and migration, were registered. Household data included information on the house (floor, walls) and services (water, sanitation, electricity); see Table 1 . All women aged 15-49years living in the households provided retrospective reproductive histories [26]. In the 2009 and 2014 updates, questions covered participation in the following interventions: access to water and latrines, microcredit, home gardening, technical education, school breakfast programs, and telecommunications. Data on food security, household assets, and women's self-rated health were part of the 2014 update.

Trained local women with at least high school education conducted the fieldwork with careful supervision. Forms were checked before computerization and returned to the field if the information was missing or suspected to be incorrect. Further quality controls after computerization included logical checks of data. Researchers carefully cleaned the data and stored these in relational databases.

\section{Outcome variable}

The outcome variable for incidence calculations and Conditional Inference Trees (CIT) analyses, adolescent pregnancy (yes/no), was derived by taking the first pregnancy in women 20-24years of age and the result of that pregnancy (live birth, stillbirth, abortion) into account. The same outcome covered different age categories and cohorts, showing trends in ABR and APR, respectively. The ABR is defined as live births per 1000 women 10-14 years old and 15-19years old, and the APR as live births, ongoing pregnancies, abortions, and stillbirths per 1000 women in the same age categories.

\section{Predictor variables}

The predictor variables on the individual level included in the CIT analyses were merged with variables at the household level referred to each individual using housing ID, for variable list see Table 1 . We included occupation (unemployed, housewife, employed, student) and education (no education, primary, secondary, higher) as reported by each woman. Also, women's self-rated health was assessed at the time of the interview by a five-point Likert scale based on the following question: "In general, how would you assess your health today?" The interviewer provided the following options: very good, good, medium, bad, or very bad. In the analyses this information was classified as good (very good, good, medium) and bad (bad, very bad) health, respectively.

The household was defined as persons residing in the household at that time. The Unsatisfied Basic Needs index [27] was composed of four components: (1) housing conditions (unsatisfied: walls of wood, cardboard, plastic and earthen floor); (2) access to water and latrine (unsatisfied: water from river, well, or bought in barrels and no latrine or toilet); (3) school enrolment of children (unsatisfied: any children 7-14 years of age not attending school); and (4) education of head of the family and ratio of dependent ( $<15 \mathrm{yrs}$. and $>65 \mathrm{yrs}$. $)$ household members to working-age members (15-65yrs.) (unsatisfied: head of the family illiterate or dropped out of primary school and ratio of dependent household members to 
Table 1 Individual and household variables in the conditional inference tree analyses of adolescent pregnancies NN-HDSS, 2014

\begin{tabular}{|c|c|c|c|c|c|c|c|}
\hline \multirow[t]{2}{*}{$\begin{array}{l}\text { Categorical } \\
\text { variables }\end{array}$} & \multirow[t]{2}{*}{ Labels } & \multicolumn{2}{|l|}{$\begin{array}{l}\text { All } 20-24 \\
n=1041\end{array}$} & \multirow{2}{*}{$\begin{array}{l}\text { Stay- } \\
\text { ers }^{\mathrm{a}} 20-24 \\
n=752 \\
\mathrm{n}\end{array}$} & \multicolumn{3}{|c|}{$\begin{array}{l}\text { Leavers }^{\mathrm{a}} 20-24 \\
n=289\end{array}$} \\
\hline & & $\mathbf{n}$ & $\%^{\mathrm{b}}$ & & $\%^{b}$ & $\mathrm{n}$ & $\%^{\mathrm{b}}$ \\
\hline \multicolumn{8}{|c|}{ Individual variables } \\
\hline \multirow{2}{*}{$\begin{array}{l}\text { Adolescent } \\
\text { Pregnancy }\end{array}$} & 0 Not given birth at age $10-19$ years & 734 & 71 & 604 & 80 & 130 & 45 \\
\hline & 1 Given birth at age $10-19$ years & 307 & 29 & 148 & 20 & 159 & 55 \\
\hline \multirow{4}{*}{$\begin{array}{l}\text { Occupa- } \\
\text { tion }\end{array}$} & 1 Unemployed & 65 & 6 & 60 & 8 & 5 & 2 \\
\hline & 2 Housewife & 730 & 70 & 462 & 61 & 268 & 93 \\
\hline & 3 Employed & 64 & 6 & 53 & 7 & 11 & 4 \\
\hline & 4 Student & 182 & 17 & 177 & 24 & 5 & 2 \\
\hline \multirow{4}{*}{$\begin{array}{l}\text { Education } \\
\text { (years of } \\
\text { schooling) }\end{array}$} & 1 No education & 131 & 13 & 72 & 10 & 59 & 20 \\
\hline & 2 Primary (6yrs) & 657 & 63 & 455 & 61 & 202 & 70 \\
\hline & 3 Secondary (5yrs) & 9 & 1 & 9 & 1 & 0 & 0 \\
\hline & 4 Higher (5yrs) & 244 & 23 & 216 & 29 & 28 & 10 \\
\hline \multirow{2}{*}{$\begin{array}{l}\text { Women's } \\
\text { self-rated } \\
\text { health }\end{array}$} & 1 Good & 636 & 61 & 476 & 63 & 160 & 55 \\
\hline & 2 Average or bad & 405 & 39 & 276 & 37 & 129 & 45 \\
\hline \multicolumn{8}{|c|}{ Household variables } \\
\hline \multirow[t]{4}{*}{$U_{B N}^{c}$} & 0 No basic need unsatisfied & 265 & 25 & 210 & 28 & 55 & 19 \\
\hline & 1 Wall is made of wood, cartons, plastic AND mud floor & 345 & 33 & 258 & 34 & 87 & 30 \\
\hline & $\begin{array}{l}2 \text { Access to water from rivers, wells, or bought in barrels AND no } \\
\text { latrine }\end{array}$ & 421 & 40 & 275 & 37 & 146 & 51 \\
\hline & $\begin{array}{l}3 \text { Children aged } 7 \text { to } 14 \text { years are not attending school OR } \\
4 \text { The head is illiterate or not completed primary school AND } \\
\text { dependency ratio }>2\end{array}$ & 10 & 1 & 9 & 1 & 1 & $<1$ \\
\hline \multirow[t]{2}{*}{ Poverty } & 0 Not poor $=U_{B N}{ }^{c} 0-1$ & 610 & 59 & 468 & 62 & 142 & 49 \\
\hline & 1 Poor $=U_{B N}{ }^{c} 2-4$ & 431 & 41 & 284 & 38 & 147 & 51 \\
\hline \multirow{3}{*}{$\begin{array}{l}\text { House wall } \\
\text { type }\end{array}$} & 1 Ceramic brick & 302 & 29 & 223 & 30 & 79 & 27 \\
\hline & 2 Adobe/wattle wall & 719 & 69 & 524 & 70 & 195 & 67 \\
\hline & 3 Other & 20 & 2 & 5 & 1 & 15 & 5 \\
\hline \multirow{6}{*}{$\begin{array}{l}\text { Water avail- } \\
\text { ability }\end{array}$} & 1 Inside pipe & 363 & 35 & 283 & 38 & 80 & 28 \\
\hline & 2 Commune post & 32 & 3 & 22 & 3 & 10 & 3 \\
\hline & 3 Own well & 222 & 21 & 170 & 22 & 52 & 18 \\
\hline & 4 Communal well & 292 & 28 & 199 & 26 & 93 & 32 \\
\hline & 5 River or Creek & 76 & 7 & 52 & 7 & 24 & 8 \\
\hline & 6 Purchased water or Other sources & 56 & 5 & 26 & 3 & 30 & 10 \\
\hline \multirow[t]{3}{*}{ Toilet type } & 1 Toilet & 23 & 2 & 19 & 3 & 4 & 1 \\
\hline & 2 Latrine & 838 & 80 & 658 & 88 & 180 & 62 \\
\hline & 3 No toilet or latrine & 180 & 17 & 75 & 10 & 105 & 36 \\
\hline \multirow{4}{*}{$\begin{array}{l}\text { Floor in } \\
\text { house }\end{array}$} & 1 Ceramic brick & 85 & 8 & 68 & 9 & 17 & 6 \\
\hline & 2 Brick of Mud or Cement & 73 & 7 & 63 & 8 & 10 & 3 \\
\hline & 3 Tiling & 331 & 32 & 248 & 33 & 83 & 29 \\
\hline & 4 Mud floor & 552 & 53 & 373 & 50 & 179 & 62 \\
\hline \multirow{2}{*}{$\begin{array}{l}\text { Electricity } \\
\text { in the house }\end{array}$} & 1 Yes & 931 & 89 & 698 & 93 & 233 & 81 \\
\hline & $2 \mathrm{No}$ & 110 & 11 & 54 & 7 & 56 & 19 \\
\hline \multirow{2}{*}{$\begin{array}{l}\text { Stove in } \\
\text { house }\end{array}$} & 1 Gas & 81 & 8 & 52 & 7 & 29 & 10 \\
\hline & 2 Wood & 960 & 92 & 700 & 93 & 260 & 90 \\
\hline \multirow{2}{*}{$\begin{array}{l}\text { Water } \\
\text { meter in use }\end{array}$} & 1 Yes & 216 & 21 & 167 & 22 & 49 & 17 \\
\hline & $2 \mathrm{No}$ & 825 & 79 & 585 & 78 & 240 & 83 \\
\hline \multirow{2}{*}{$\begin{array}{l}\text { Microcredit } \\
\text { in } \mathrm{HH}^{\mathrm{c}}\end{array}$} & 1 Yes & 138 & 13 & 108 & 14 & 30 & 10 \\
\hline & $2 \mathrm{No}$ & 903 & 87 & 644 & 86 & 259 & 90 \\
\hline
\end{tabular}


Table 1 (continued)

\begin{tabular}{|c|c|c|c|c|c|c|c|}
\hline \multirow{2}{*}{$\begin{array}{l}\text { Technical } \\
\text { training in } \\
\mathrm{HH}^{\mathrm{d}}\end{array}$} & 1 Yes & 162 & 16 & 133 & 18 & 29 & 10 \\
\hline & $2 \mathrm{No}$ & 879 & 84 & 619 & 82 & 260 & 90 \\
\hline \multirow{2}{*}{$\begin{array}{l}\text { Home gar- } \\
\text { den in } \mathrm{HH}^{\mathrm{d}}\end{array}$} & 1 Yes & 61 & 6 & 49 & 7 & 12 & 4 \\
\hline & $2 \mathrm{No}$ & 980 & 94 & 703 & 93 & 277 & 96 \\
\hline \multirow{2}{*}{$\begin{array}{l}\text { Home gar- } \\
\text { den in use }\end{array}$} & 1 Yes & 43 & 4 & 35 & 5 & 8 & 3 \\
\hline & $2 \mathrm{No}$ & 998 & 96 & 717 & 95 & 281 & 97 \\
\hline \multirow{4}{*}{$\begin{array}{l}\text { Anxiety in } \\
\mathrm{HH}^{d} \text { for lack } \\
\text { of food }\end{array}$} & 0 Never & 166 & 16 & 122 & 16 & 44 & 15 \\
\hline & 1 Rarely (1-2 times) & 429 & 41 & 299 & 40 & 130 & 45 \\
\hline & 2 Sometimes (3-10 times) & 241 & 23 & 175 & 23 & 66 & 23 \\
\hline & 3 Often (> 10 times) & 205 & 20 & 156 & 21 & 49 & 17 \\
\hline \multirow{4}{*}{$\begin{array}{l}\text { Inability in } \\
H H^{d} \text { to eat } \\
\text { preferred } \\
\text { food }\end{array}$} & O Never & 163 & 16 & 111 & 15 & 52 & 18 \\
\hline & 1 Rarely (1-2 times) & 436 & 42 & 307 & 41 & 129 & 45 \\
\hline & 2 Sometimes (3-10 times) & 344 & 33 & 260 & 35 & 84 & 29 \\
\hline & 3 Often (> 10 times) & 98 & 9 & 74 & 10 & 24 & 8 \\
\hline \multirow{4}{*}{$\begin{array}{l}\text { Limited } \\
\text { variation of } \\
\text { food in } \mathrm{HH}^{\mathrm{d}} \\
\text { due to lack of } \\
\text { food }\end{array}$} & o Never & 221 & 21 & 157 & 21 & 64 & 22 \\
\hline & 1 Rarely (1-2 times) & 483 & 46 & 344 & 46 & 139 & 48 \\
\hline & 2 Sometimes (3-10 times) & 267 & 26 & 197 & 26 & 70 & 24 \\
\hline & 3 Often (> 10 times) & 70 & 7 & 54 & 7 & 16 & 6 \\
\hline \multirow{4}{*}{$\begin{array}{l}\text { Few kinds } \\
\text { of food con- } \\
\text { sumed in } \mathrm{HH}^{\mathrm{d}} \\
\text { due to lack of } \\
\text { food }\end{array}$} & 0 Never & 212 & 20 & 154 & 7 & 58 & 20 \\
\hline & 1 Rarely (1-2 times) & 505 & 49 & 358 & 48 & 147 & 51 \\
\hline & 2 Sometimes (3-10 times) & 264 & 25 & 192 & 26 & 72 & 25 \\
\hline & 3 Often (> 10 times) & 60 & 6 & 48 & 6 & 12 & 4 \\
\hline \multirow{4}{*}{$\begin{array}{l}\text { Reduction } \\
\text { of portion } \\
\text { sizes of meals } \\
\text { in } \mathrm{HH}^{\mathrm{d}} \text { due to } \\
\text { lack of food }\end{array}$} & O Never & 295 & 28 & 213 & 28 & 82 & 28 \\
\hline & 1 Rarely (1-2 times) & 494 & 47 & 348 & 46 & 146 & 51 \\
\hline & 2 Sometimes (3-10 times) & 207 & 20 & 155 & 21 & 52 & 18 \\
\hline & 3 Often (> 10 times) & 45 & 4 & 36 & 5 & 9 & 3 \\
\hline \multirow{4}{*}{$\begin{array}{l}\text { Fewer } \\
\text { meals con- } \\
\text { sumed in } \mathrm{HH}^{\mathrm{d}} \\
\text { due to lack of } \\
\text { food }\end{array}$} & O Never & 454 & 44 & 331 & 44 & 123 & 43 \\
\hline & 1 Rarely (1-2 times) & 408 & 39 & 285 & 38 & 123 & 43 \\
\hline & 2 Sometimes (3-10 times) & 149 & 14 & 112 & 15 & 37 & 13 \\
\hline & 3 Often (> 10 times) & 30 & 3 & 24 & 3 & 6 & 2 \\
\hline \multirow{3}{*}{$\begin{array}{l}\text { No food } \\
\text { to eat in } \mathrm{HH}^{\mathrm{d}} \\
\text { due to lack of } \\
\text { resources }\end{array}$} & 0 Never & 757 & 73 & 546 & 73 & 211 & 73 \\
\hline & 1 Rarely (1-2 times) & 231 & 22 & 164 & 22 & 67 & 23 \\
\hline & 2 Sometimes (3-10 times) and often (> 10 times) & 53 & 5 & 42 & 6 & 11 & 4 \\
\hline \multirow{3}{*}{$\begin{array}{l}\mathrm{HH}^{\mathrm{d}} \text { going } \\
\text { to sleep hun- } \\
\text { gry due to } \\
\text { lack of food }\end{array}$} & 0 Never & 913 & 88 & 654 & 87 & 259 & 90 \\
\hline & 1 Rarely (1-2 times) & 97 & 9 & 72 & 10 & 25 & 9 \\
\hline & 2 Sometimes (3-10 times) and often (> 10 times) & 31 & 3 & 26 & 3 & 5 & 2 \\
\hline \multirow{3}{*}{$\begin{array}{l}\quad H^{d} \text { hav- } \\
\text { ing days of } \\
\text { hunger due } \\
\text { to insufficient } \\
\text { amount of } \\
\text { food }\end{array}$} & O Never & 958 & 92 & 688 & 91 & 270 & 93 \\
\hline & 1 Rarely (1-2 times) & 62 & 6 & 45 & 6 & 17 & 6 \\
\hline & 2 Sometimes (3-10 times) and often (> 10 times) & 21 & 2 & 19 & 3 & 2 & 1 \\
\hline \multirow{4}{*}{$\begin{array}{l}\text { TV antenna } \\
\text { in } \mathrm{HH}^{\mathrm{b}}\end{array}$} & 1 Parabolic antenna & 149 & 14 & 125 & 17 & 24 & 8 \\
\hline & 2 Normal antenna & 427 & 41 & 334 & 44 & 93 & 32 \\
\hline & 3 Handmade antenna & 88 & 8 & 72 & 10 & 16 & 6 \\
\hline & 4 No antenna & 377 & 36 & 221 & 29 & 156 & 54 \\
\hline \multirow[t]{2}{*}{ Car in $\mathrm{HH}^{\mathrm{d}}$} & 1 Yes & 31 & 3 & 28 & 4 & 3 & 1 \\
\hline & $2 \mathrm{No}$ & 1010 & 97 & 724 & 96 & 286 & 99 \\
\hline \multirow{2}{*}{$\begin{array}{l}\text { Motorbike } \\
\text { in } \mathrm{HH}^{d}\end{array}$} & 1Yes & 123 & 12 & 88 & 12 & 35 & 12 \\
\hline & $2 \mathrm{No}$ & 918 & 88 & 664 & 88 & 254 & 88 \\
\hline
\end{tabular}


Table 1 (continued)

\begin{tabular}{|c|c|c|c|c|c|c|c|c|}
\hline \multirow[t]{2}{*}{ Bike in $\mathrm{HH}^{\mathrm{d}}$} & 1 Yes & & 184 & 18 & 133 & 18 & 51 & 18 \\
\hline & $2 \mathrm{No}$ & & 857 & 82 & 619 & 82 & 238 & 82 \\
\hline \multirow{2}{*}{$\begin{array}{l}\text { Horse in } \\
\mathrm{HH}^{\mathrm{d}}\end{array}$} & 1 Yes & & 296 & 28 & 241 & 32 & 55 & 19 \\
\hline & $2 \mathrm{No}$ & & 745 & 72 & 511 & 68 & 234 & 81 \\
\hline \multirow{2}{*}{$\begin{array}{l}\text { Refrigera- } \\
\text { tor in } H^{d}\end{array}$} & 1 Yes & & 363 & 35 & 298 & 40 & 65 & 22 \\
\hline & $2 \mathrm{No}$ & & 678 & 65 & 454 & 60 & 224 & 78 \\
\hline \multirow{2}{*}{$\begin{array}{l}\text { Sewing } \\
\text { machine in } \\
\mathrm{HH}^{d}\end{array}$} & 1 Yes & & 69 & 7 & 62 & 8 & 7 & 2 \\
\hline & $2 \mathrm{No}$ & & 972 & 93 & 690 & 92 & 282 & 98 \\
\hline \multirow{2}{*}{$\begin{array}{l}\text { Computer } \\
\text { in } \mathrm{HH}^{\mathrm{d}}\end{array}$} & 1 Yes & & 56 & 5 & 44 & 6 & 12 & 4 \\
\hline & $2 \mathrm{No}$ & & 985 & 95 & 708 & 94 & 277 & 96 \\
\hline \multirow{2}{*}{$\begin{array}{c}\text { Tortilla } \\
\text { oven in } \mathrm{HH}^{\mathrm{d}}\end{array}$} & 1 Yes & & 192 & 18 & 173 & 23 & 19 & 7 \\
\hline & $2 \mathrm{No}$ & & 849 & 82 & 579 & 77 & 270 & 93 \\
\hline \multirow{2}{*}{$\begin{array}{l}\text { Stove with } \\
\text { a chimney in } \\
\mathrm{HH}^{\mathrm{d}}\end{array}$} & 1 Yes & & 21 & 2 & 15 & 2 & 6 & 2 \\
\hline & $2 \mathrm{No}$ & & 1020 & 98 & 737 & 98 & 283 & 98 \\
\hline \multirow{2}{*}{$\begin{array}{l}\text { Sex of } \mathrm{HH}^{\mathrm{d}} \\
\text { head }\end{array}$} & 1 Female head of $\mathrm{HH}^{\mathrm{d}}$ & & 250 & 24 & 208 & 28 & 42 & 15 \\
\hline & 2 Male head of $\mathrm{HH}^{\mathrm{d}}$ & & 791 & 76 & 544 & 72 & 247 & 85 \\
\hline \multirow{2}{*}{$\begin{array}{l}\text { Illiterate } \\
\text { living in } \mathrm{HH}^{\mathrm{d}}\end{array}$} & 0 No illiterate in $\mathrm{HH}^{d}$ & & 749 & 72 & 508 & 68 & 241 & 83 \\
\hline & 1 Illiterate in $\mathrm{HH}^{\mathrm{d}}$ & & 292 & 28 & 244 & 32 & 48 & 17 \\
\hline \multirow{4}{*}{$\begin{array}{l}\text { Highest } \\
\text { education in } \\
\mathrm{HH}^{\mathrm{d}}\end{array}$} & 0 No education or Primary school & & 174 & 17 & 82 & 11 & 92 & 32 \\
\hline & 2 Secondary school & & 522 & 50 & 374 & 50 & 148 & 51 \\
\hline & 3 Technical education & & 82 & 8 & 67 & 9 & 15 & 5 \\
\hline & 4 University education & & 263 & 25 & 229 & 30 & 34 & 12 \\
\hline \multirow{2}{*}{$\begin{array}{l}\text { Immigra- } \\
\text { tion in } \mathrm{HH}^{\mathrm{d}}\end{array}$} & $\mathrm{O}$ No immigration in $\mathrm{HH}^{\mathrm{d}}$ & & 464 & 45 & 412 & 55 & 52 & 18 \\
\hline & 1 Immigration in $\mathrm{HH}^{d}$ & & 577 & 55 & 340 & 45 & 237 & 82 \\
\hline \multirow{2}{*}{$\begin{array}{l}\text { Emigration } \\
\text { in } \mathrm{HH}^{\mathrm{d}}\end{array}$} & 0 No emigration in $\mathrm{HH}^{d}$ & & 382 & 37 & 207 & 28 & 175 & 61 \\
\hline & 1 Emigration in $\mathrm{HH}^{\mathrm{d}}$ & & 659 & 63 & 545 & 72 & 114 & 39 \\
\hline \multirow{2}{*}{$\begin{array}{l}\qquad \mathrm{HH}^{\mathrm{C}} \text { mem- } \\
\text { ber immi- } \\
\text { grated from } \\
\text { a foreign } \\
\text { country }\end{array}$} & 0 No immigration from another country in a household & & 938 & 90 & 658 & 88 & 280 & 97 \\
\hline & $1 \mathrm{Immigration}$ from another country in $\mathrm{HH}^{\mathrm{d}}$ & & 103 & 10 & 94 & 12 & 9 & 3 \\
\hline \multirow{2}{*}{$\begin{array}{l}\qquad \mathrm{HH}^{\mathrm{d}} \\
\text { member } \\
\text { emigrated } \\
\text { to a foreign } \\
\text { country }\end{array}$} & 0 No emigration to another country in $\mathrm{HH}^{\mathrm{d}}$ & & 880 & 85 & 621 & 83 & 259 & 90 \\
\hline & 1 Emigration to another country in $\mathrm{HH}^{\mathrm{d}}$ & & 161 & 15 & 131 & 17 & 30 & 10 \\
\hline \multirow{2}{*}{$\begin{array}{l}\text { Children } \\
(<15 y r s .) \text { In } \\
H H^{d} \text { working }\end{array}$} & 0 No & & 1017 & 98 & 732 & 97 & 285 & 99 \\
\hline & 1 Yes & & 24 & 2 & 20 & 3 & 4 & 1 \\
\hline \multicolumn{9}{|c|}{ Continuous variables } \\
\hline & $\begin{array}{l}\text { All } 20-24 \\
n=1041\end{array}$ & & $\begin{array}{l}\text { Stayers }^{\mathrm{b}} 20-24 \\
n=752\end{array}$ & & & $\begin{array}{l}\text { Leavers }^{\mathrm{b}} \\
n=\mathbf{2 8 9}\end{array}$ & & \\
\hline & Mean (Median) & Min/Max & Mean (Median) & & Min/Max & $\begin{array}{l}\text { Mean } \\
\text { (Median) }\end{array}$ & Min/Max & \\
\hline $\begin{array}{l}\text { No of adults } \\
\text { in } \mathrm{HH}^{d}\end{array}$ & $6.2(6.0)$ & $1 / 19$ & $7.0(7.0)$ & & $2 / 19$ & $4.2(2.0)$ & $1 / 17$ & \\
\hline $\begin{array}{l}\text { No in } \mathrm{HH}^{\mathrm{d}} \text { not } \\
\text { working }\end{array}$ & $3.4(3.0)$ & $0 / 13$ & $4.0(4.0)$ & & $0 / 13$ & $1.9(1.0)$ & 0/9 & \\
\hline $\begin{array}{l}\text { No in } \mathrm{HH}^{\mathrm{d}} \\
\text { working }\end{array}$ & $1.7(1.0)$ & $0 / 6$ & $1.9(2.0)$ & & $0 / 6$ & $1.3(1.0)$ & $0 / 5$ & \\
\hline $\begin{array}{l}\text { No of work- } \\
\text { ing adults } \\
(>=15 \mathrm{yrs} .) \text { in } \\
\mathrm{H} \mathrm{H}^{\mathrm{d}}\end{array}$ & $1.7(1.0)$ & $0 / 6$ & $1.9(2.0)$ & & $0 / 6$ & $1.3(1.0)$ & $0 / 5$ & \\
\hline
\end{tabular}


Table 1 (continued)

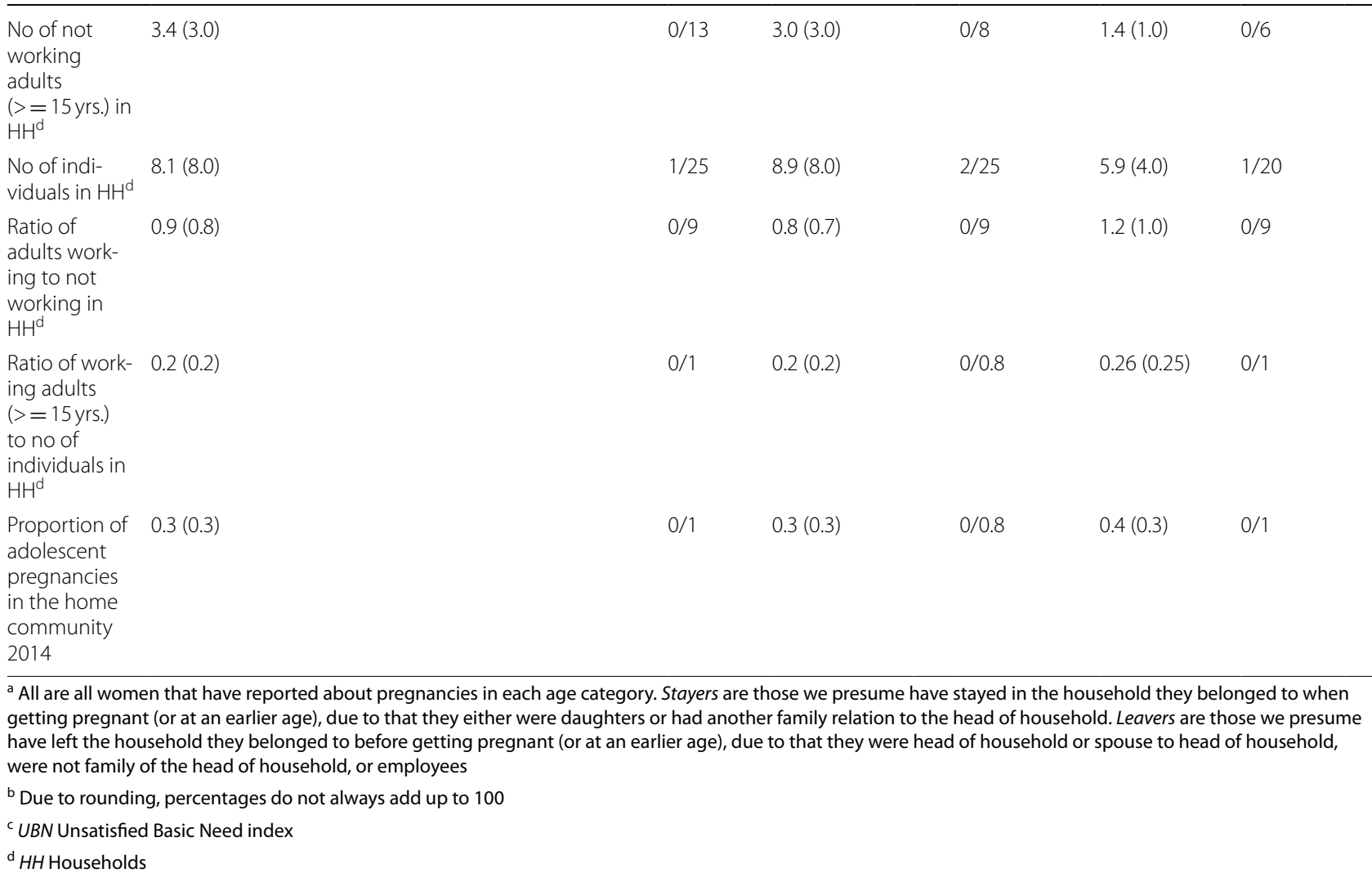

working-age members. $>2.0$ ). Each component rendered a score of zero if satisfied, and one, if unsatisfied. Thus, the total sum varied from zero to four. Households with zero or one unsatisfied basic need were considered nonpoor, while poor households had two to four unsatisfied basic needs [25]. Characteristics of houses and households were also included in the analyses, such as the material of walls, floor, access to electricity, type of stove, access to water, and type of toilet. The interventions implemented in the area were represented by householdrelated information on such participation. The presence of a water meter indicated that the household had got water installed as part of the last decade's interventions. Also, information was included on previous and current participation in home gardening, if anyone in the household had received microcredit or had participated in technical training.

The nine-item Household Food Insecurity Access Scale, version 3, was used [28]. This scale covers experiences regarding 1 ) anxiety in the household due to lack of food; 2) inability to eat preferred food because of lack of resources; 3 ) limited variety of food due to lack of resources; 4) consumption of few kinds of food because of lack of resources; 5) reduction of portion sizes of meals due to lack of food; 6) consumption of fewer meals per day because of lack of food; 7) no food to eat in the household because lack of resources; 8) going to sleep at night hungry due to lack of food, and 9) days of hunger because of insufficient amounts of food to eat. The respondents were either the head of the household or the person responsible for the household expenditure and food preparation and they reported on the food security situation during the last 4 weeks. For each affirmative answer, the person provided additional information on the frequency in a four-point scale (never, rarely, sometimes, often).

Included household assets were having a TV antenna, car, motorbike, bike, horse, refrigerator, sewing machine, computer, tortilla oven, and a chimney for the woodburning stove.

We also included gender of household head, any illiteracy, the highest education level in the household (none, primary, secondary, technical, university education) and if the household had children below age 15, working. Migration was defined as a household member aged 18-65 who migrated in or out of the household since the latest update (5yrs.) and data were included on the 
household level on in- and out-migration, including to and from foreign countries.

We constructed variables on the number of adults and children living in the household, number of adults and children working in the household, number of adults not working in the household, and the ratio between adults working and not working in household, as well as the ratio between adults working and number of individuals in the household (see Table 1). We also included a variable on the community level adolescent pregnancy proportion. A community in Cuatro Santos is a group of households with geographical proximity, and for the 2014cycle, we counted 71 communities with a mean of 81.6 of households (SD 58.01) in each community. The adolescent pregnancy proportion was calculated as the percentage of pregnancies in 10-19-year-old females per community as reported at the moment of the 2014 interview by women aged 20-24 that gave the first birth between 10 and 19 years of age. In total, the data set contained 53 variables.

\section{Analytical methods}

For the annual rate of ABR (live births per 1000 women 10-14 and 15-19years of age, respectively) and APR (live births, ongoing pregnancies, abortions, and stillbirths per 1000 women in the same age groups) we used the first live birth at 10-14 and 15-19years of age. We included reports by women aged $15-19$ and $20-24$ at the time of the interview.

We determined the annual incidence rate of pregnancies between 15 and 19 years (per 1000 person-years) for the 3 years preceding the survey using the first birth reported by women aged 20-24, at the time of interview for each NN-HDSS cycle. We calculated three-years moving averages of incidence rates to display the incidence trend (Fig. 1). We based the 2006 rate on averaged data from the 2007 and 2009 cycles. The time between the two last cycles was 5 years, which implies that there were no calculated incidences for 2009 and 2010. We used the Cohort software (Department of Epidemiology and Global Health in cooperation with Umeå University data center, Umeå, Sweden) to calculate person time in the study.

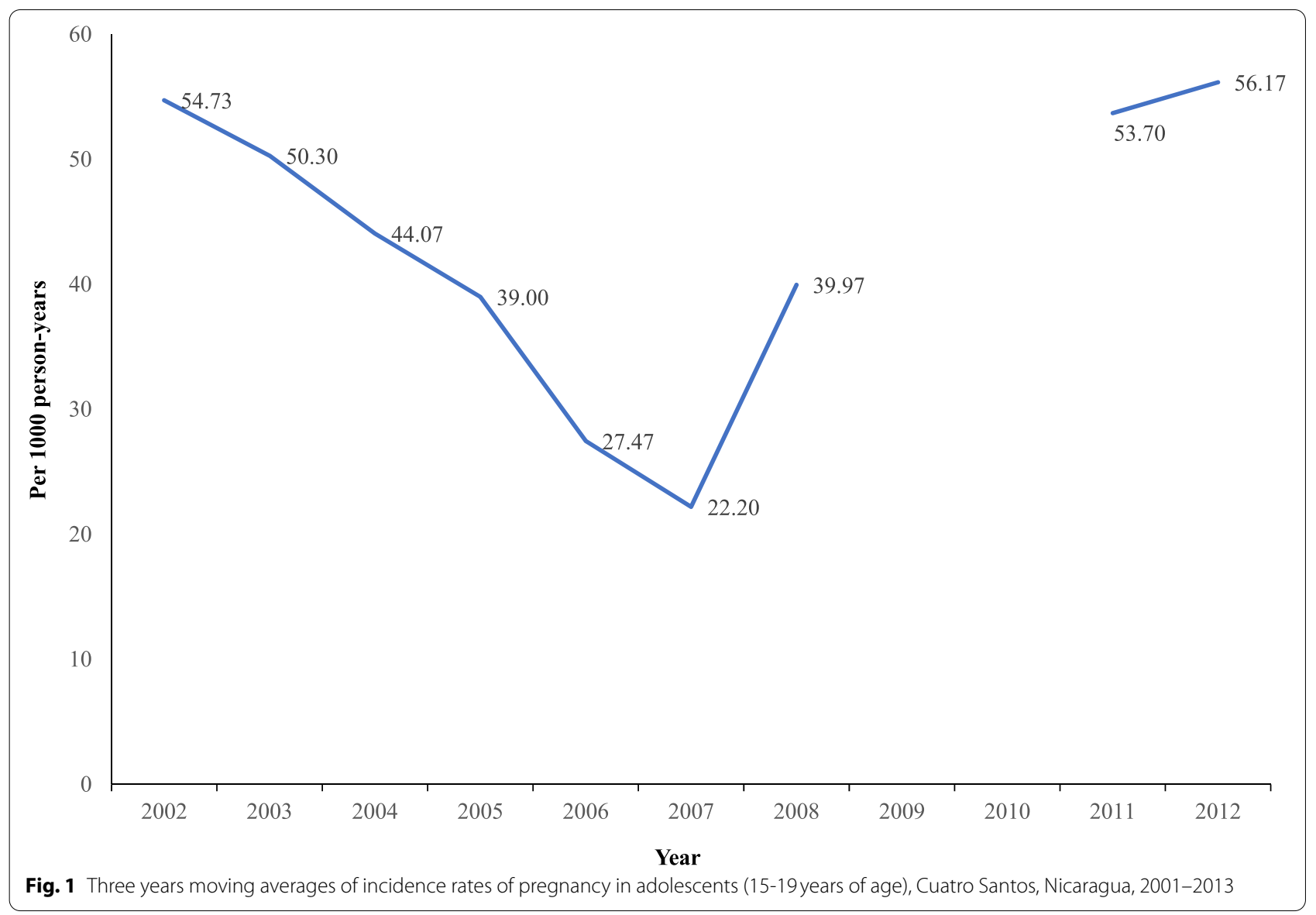




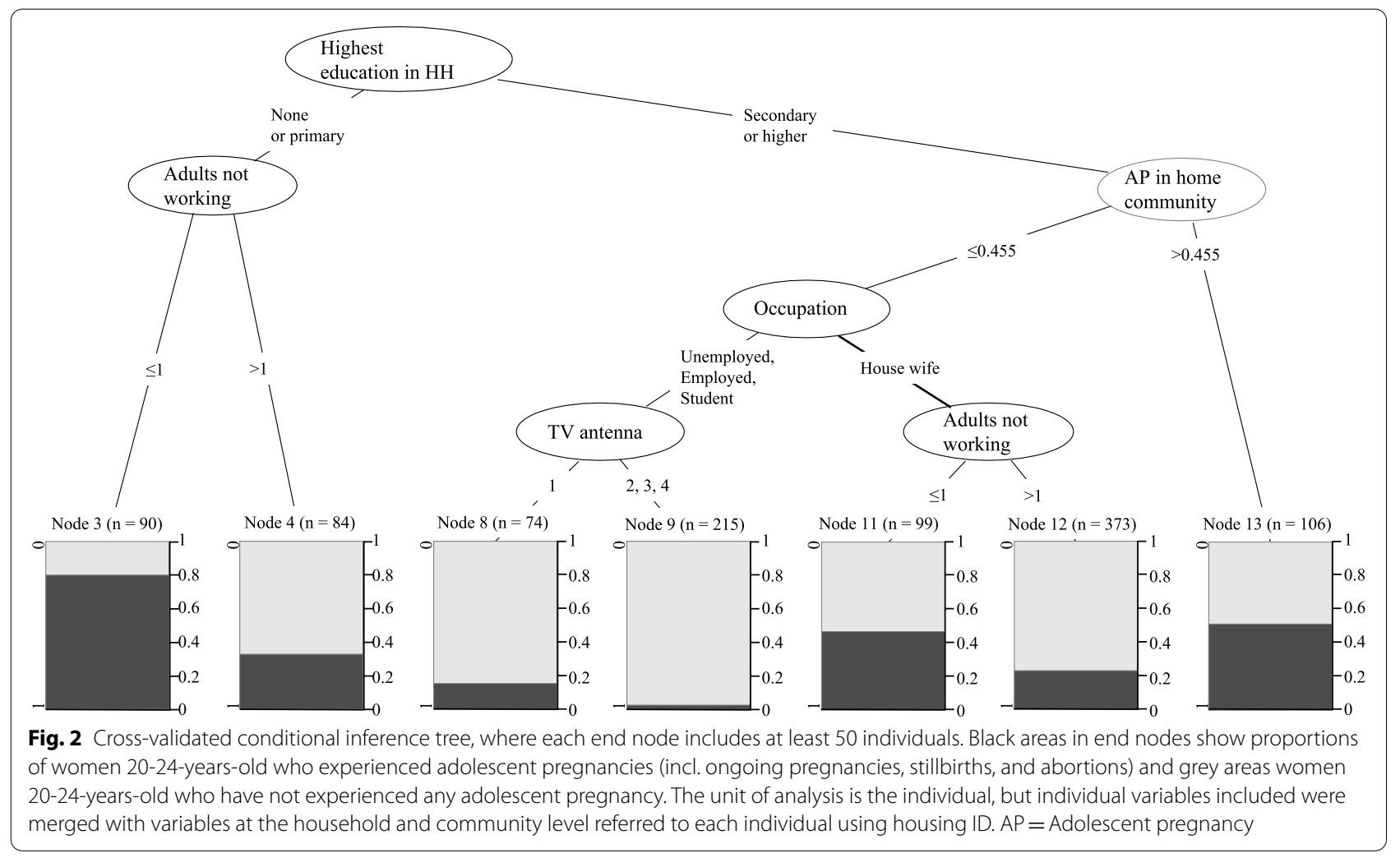

The CIT analyses included all women in the 20-24 age group with the outcome of adolescent pregnancy (yes/ no) and in subsets of data on stayers and leavers as presented below. The number of candidate predictors evaluated for inclusion was 52 (Table 1, Fig. 2, Additional file 1: Fig. S1 and Additional file 2: Fig. S2). CIT is one of the newer decision tree frameworks used in data mining that allows for specifying an arbitrarily high number of predictor variables, handling variables of different types, automatically discovering complex interactions between predictor variables, and including them into the model $[29,30]$. The method embeds a statistical hypothesistesting framework into a recursive partitioning algorithm for model building [30].

The informants relatively often reported individual and household-level information used as predictors after having an adolescent pregnancy. Thus, these variables may be a consequence of the outcome (adolescent pregnancy) rather than a 'risk factor' for the outcome. To restrict the possibility of this error, we split the data into two subsets labeled "stayers" and "leavers." These two subsets of data were analyzed separately for 20-24-year-old women. Stayers, we presumed, had stayed in the household they belonged to at the time of pregnancy (or at an earlier age). They were either daughters or had another family relation to the head of the household rather than being the partner. Leavers were those presumed to have left the home they were associated with before getting pregnant (or at an earlier age), based on that they were head of household or spouse to head of household, i.e., they were not family to the head of household or employees. Thus, by using these two subsets, the household variables should be similar for stayers as when they got pregnant but different and maybe a consequence of the adolescent pregnancy, for the leavers.

Cross-validation, a well-established method, was applied to select the tree of optimal size and the best predictive performance [31]. The minimum number of observations in each terminal node (subgroup) was limited to 50 to ensure public health significance. We used programming language $R$ version 3.2.4 [32] and the "party" package [33] for all analyses.

\section{Results}

In the 2014 Northern Nicaraguan HDSS update, 5233 households were inhabited and provided data. The total number of 15-19-year-old and 20-24-year-old women included in the calculation of ABR and APR in the four cycles of the NN-HDSS varied between 865 and 1623 (Table 2). See Table 3 for the total number of women aged 10-19years with pregnancies and the person-years included in the incidence calculations of adolescent 
Table 2 Adolescent birth rates and pregnancy rates reported among 15-19-years-olds and 20-24-years-olds by cycle of NN-HDSS, 2004-2014

\begin{tabular}{|c|c|c|c|c|}
\hline NN-HDSS cycle & 2004 & 2007 & 2009 & 2014 \\
\hline \multicolumn{5}{|l|}{ Age group 15-19 } \\
\hline No. of women & 1273 & 1467 & 1623 & 1389 \\
\hline Live Births (10-19) & 146 & 150 & 126 & 186 \\
\hline Adolescent Birth Rate ABR $(95 \% \mathrm{Cl})$ & $114.7(97.1-132)$ & $102.2(86.7-117.8)$ & $77.6(64.6-90.6)$ & $133.9(116.0-151.8)$ \\
\hline Live births (10-14) & 14 & 13 & 5 & 18 \\
\hline Adolescent Birth Rate ABR (95\%Cl) & $11.0(5.2-16.7)$ & $8.9(4.0-13.6)$ & $3.1(0.3-5.7)$ & $13.0(7.0-18.9)$ \\
\hline Live births (15-19) & 132 & 137 & 121 & 168 \\
\hline Adolescent Birth Rate ABR $(95 \% \mathrm{Cl})$ & $103.7(86.9-120.4)$ & $93.4(78.5-108.3)$ & $74.6(61.7-87.3)$ & $121.0(103.8-138-1)$ \\
\hline No. of women & 1273 & 1467 & 1623 & 1389 \\
\hline Pregnancies 10-19 & 201 & 187 & 148 & 241 \\
\hline Adolescent Pregnancy Rates APR (95\%Cl) & $157.9(137.9-177.9)$ & $127.5(110.4-144.5)$ & $91.2(77.1-105.2)$ & $173.5(153.6-193.4)$ \\
\hline Pregnancies 10-14 & 16 & 14 & 6 & 18 \\
\hline Adolescent Pregnancy Rates APR $(95 \% \mathrm{Cl})$ & $12.6(6.4-18.6)$ & $9.5(4.5-14.5)$ & $3.7(0.7-6.6)$ & $13.0(7.0-18.9)$ \\
\hline Pregnancies 15-19 & 185 & 173 & 142 & 223 \\
\hline Adolescent Pregnancy Rates APR $(95 \% \mathrm{Cl})$ & $145.3(126.0-164.7)$ & $117.9(101.4-134.4)$ & $87.5(73.7-101.2)$ & $160.5(141.2-179.9)$ \\
\hline \multicolumn{5}{|l|}{ Age group 20-24 } \\
\hline No. of women & 982 & 865 & 886 & 1292 \\
\hline Live Births (10-19) & 406 & 188 & 118 & 423 \\
\hline Adolescent Birth Rate ABR $(95 \% \mathrm{Cl})$ & $413.4(382.6-444.2)$ & $217.3(189.9-244.8)$ & $133.2(110.8-155.6)$ & $327.4(301.8-353.0)$ \\
\hline Live births (10-14) & 24 & 8 & 7 & 13 \\
\hline Adolescent Birth Rate ABR $(95 \% \mathrm{Cl})$ & $24.4(14.7-34.1)$ & $9.2(2.8-15.6)$ & $7.9(2.0-13.7)$ & $10.1(4.6-15.5)$ \\
\hline Live births (15-19) & 382 & 180 & 111 & 410 \\
\hline Adolescent Birth Rate ABR $(95 \% \mathrm{Cl})$ & $389.0(358.5-419.5)$ & $208.1(181.0-235.1)$ & $125.3(103.5-147.1)$ & $317.3(292.0-342.7)$ \\
\hline No. of women & 982 & 865 & 886 & 1292 \\
\hline Pregnancies 10-19 & 427 & 193 & 123 & 447 \\
\hline Adolescent Pregnancy Rates APR $(95 \% \mathrm{Cl})$ & $434.8(403.8-465.8)$ & $223.1(195.4-250.9)$ & $138.8(116.1-161.6)$ & $346.0(320.0-371.9)$ \\
\hline Pregnancies 10-14 & 26 & 8 & 7 & 14 \\
\hline Adolescent Pregnancy Rates APR $(95 \% \mathrm{Cl})$ & $26.4(16.4-36.5)$ & $9.2(2.8-15.6)$ & $7.9(2.0-13.7)$ & $10.8(5.1-16.4)$ \\
\hline Pregnancies 15-19 & 401 & 185 & 116 & 433 \\
\hline Adolescent Pregnancy Rates APR $(95 \% \mathrm{Cl})$ & $408.3(377.6-439.1)$ & $213.9(186.5-241.2)$ & $130.9(108.7-153.1)$ & $335.1(309.4-360.9)$ \\
\hline
\end{tabular}

pregnancies. The CIT analysis included data on 1041 20-24-year-old women after excluding individuals with missing values. Table 1 shows the characteristics of the included women.

Trends of adolescent births and pregnancies 2004-14 in Cuatro Santos, Nicaragua

Table 2 provides the ABR and APR for girls and young women 10-14years of age and 15-19-years of age. Overall, both ABR and APR decreased from 2004 to 2009 , followed by an increase in 2014. The difference between reported live births and pregnancies was substantial, especially in the younger age group. In the age group 15-19years, $71-85 \%$ were live births, and 15-29\% constituted present pregnancies, stillbirths, or abortions. In the older age group, the proportion of stillbirths and abortions was $3-5 \%$ of all pregnancies. In the $10-14$ years group, $0-7 \%$ of pregnancies were stillbirths or abortions, as reported by both age groups of informants.

\section{Incidence trend of adolescent pregnancies 2001-2013 in Cuatro Santos, Nicaragua}

The incidence rates of pregnancies per 1000 person-years for women 15-19years of age for the cycles of the $\mathrm{NN}$ HDSS varied from 17.5 to 75.1 , as seen in Table 3. The trend analysis (Fig. 1) showed a steep decline in the incidence of adolescent pregnancies from 2001 to 2007, followed by a steep upwards turn to 2008 , and after that, an increase to higher levels 2011-2012. 
Table 3 Incidence rates of pregnancies per person-years in women aged 15-19years in the NN-HDSS cycles as reported by 20-24-years-old women. The rates were calculated for the 3 years preceding the survey

\begin{tabular}{|c|c|c|c|c|}
\hline Year & Pregnancies (15-19-years) & $\begin{array}{l}\text { Mean age at pregnancy (years of } \\
\text { age) }\end{array}$ & Person-years & $\begin{array}{l}\text { Crude incidence } x \\
1000 \text { person-years }\end{array}$ \\
\hline \multicolumn{5}{|c|}{ Baseline (end 2003/2004) } \\
\hline 2001 & 43 & 18.7 & 572.4 & 75.1 \\
\hline 2002 & 27 & 19.2 & 503.6 & 53.6 \\
\hline 2003 & 17 & 19.6 & 440.4 & 38.5 \\
\hline \multicolumn{5}{|c|}{ First cycle (2007) } \\
\hline 2004 & 45 & 18.2 & 728.0 & 61.8 \\
\hline 2005 & 23 & 19.0 & 657.2 & 34.9 \\
\hline 2006 & 14 & 19.4 & 603.4 & 23.2 \\
\hline \multicolumn{5}{|c|}{ Second cycle (2009) } \\
\hline 2006 & 14 & 18.6 & 799.6 & 17.5 \\
\hline 2007 & 21 & 18.7 & 770.0 & 27.2 \\
\hline 2008 & 14 & 19.4 & 729.6 & 19.1 \\
\hline \multicolumn{5}{|c|}{ Third cycle (2014) } \\
\hline 2011 & 68 & 18.4 & 923.3 & 73.6 \\
\hline 2012 & 56 & 19.0 & 817.9 & 68.4 \\
\hline 2013 & 19 & 19.3 & 716.3 & 26.5 \\
\hline
\end{tabular}

\section{Predictors for adolescent pregnancies reported by 20-24-year-old women}

In the CIT analysis, including all 20-24-year-old women $(n=1041)$, the most crucial splitting variable was "highest education level in the household," followed by "nonworking adults in the household" and "proportion of adolescent pregnancies in the community" (Fig. 2). Figure 2, (node eight and nine, $n=74+215$ ) shows the subgroups of women with the least likelihood of having experienced a pregnancy in adolescence. They were those who lived in a household with secondary or higher education, in a community with a lower level of adolescent pregnancies $(\leq 0.455$, the mean was 0.3 for this variable and group of women as seen in Table 1), and were not housewives. Women with the highest likelihood of having experienced an adolescent pregnancy (Fig. 2, node three, $n=90$ ) lived in a household with no education or only primary school, and where the number of adults not working was one or zero. The second highest likelihood of having experienced an adolescent pregnancy (Fig. 2, node $13, n=106$ ) had women who lived in a household with secondary school or higher and in a community, where the proportion of adolescent pregnancies was higher ( $>0.455$, the mean was 0.3 for this variable and group of women as seen in Table 1 ).

The analysis of 20-24-year-old stayers (presumed to have stayed in the household they belonged to when getting pregnant, or at an earlier age, $n=752$, Additional file, Fig. S1) showed that women with a higher proportion of adolescent pregnancy in the community and with no education or primary school showed the highest occurrence of adolescent pregnancies.

Additional file, Fig. S2 shows the 20-24-year-old leavers (presumed to have left the household they belonged to before getting pregnant, or at an earlier age). Among leavers, the highest proportion of pregnancies was found in the group with no education, followed by those with primary or higher education and a higher percentage of adolescent pregnancies in the community.

\section{Discussion}

To our knowledge, this is the first study that examined recent time-trend data of adolescent pregnancy from rural settings through a valid prospective demographic surveillance system and analyzed a large number of related factors that classical statistical methods are unable to handle. In these Northern Nicaraguan communities, adolescent pregnancies and live births decreased from 2004 to 2009 , followed by a marked increase up to 2014. The adolescent pregnancy incidence rates 20012013 had a similar shape. The curve steadily dropped from 2001 to 2007, followed by a steep upward trend from 2007 to 2008 and increasing even more during the two last years of study. The 20-24-year-old women, who had experienced an adolescent pregnancy, more frequently lived in a household with a low education level and where most adults were working. Further, the proportion of adolescent pregnancies in the home community was positively associated with a higher occurrence of 
adolescent pregnancies. Our results are generalizable to the rural areas of Nicaragua and similar settings in Central America and the Caribbean, however the specific findings related to the context might vary from setting to setting.

Almost all literature on 'risk factors' for adolescent pregnancies refers to results on births retrospectively reported by teenage mothers, studied by cross-sectional designs. As this approach does not capture the temporality of risk factors, it implies that many reported risk factors might be the consequences of adolescent pregnancy, for example, marriage, low education, and low income. Neal and co-authors also suggested this in 2018 [12]. A more appropriate labeling would be to describe the identified factors as associated with the retrospectively reported adolescent birth.

We tried to overcome the temporality problem by splitting our data set into stayers and leavers; however, that action only partly solved the problem, since individual variables in most cases were collected after the pregnancy. Nevertheless, as the household variables could be the same among the stayers as when the pregnancy happened, while they probably have changed for the leavers, it can explain the difference seen in the CIT analysis on the community adolescent pregnancy proportion being more critical among the stayers than among the leavers.

The decrease 2004-2007 of ABR for the 15-19-year group coincided with the country decline reported in PAHO-2019 (2004-7), e.g., the overall ABR changing from 111.5 to 106.4 [20]. A study that examined data from four nationally representative surveys from 1987 to 2007 in Central America showed that the percentage of adolescents, who had had a live birth in Nicaragua, was the highest, $26 \%$ in 1987, but after that reduced to $20 \%$ in 2007 [34].

The strong association between a low educational level and adolescent pregnancy is probably, at least partly, a consequence of adolescent pregnancy, forcing pregnant teenagers to leave school. This contrasts with the law that prohibits public schools from expelling girls who become pregnant (Nicaraguan Child and Adolescence Code Law, Law No. 287). Irrespective of the law, social pressure makes girls leave school. Our results indicate that women in their 20ies, who had an adolescent pregnancy, were not able to overcome this educational disadvantage.

Living in households with many working adults was common among women who had experienced an adolescent pregnancy. This fact contradicts earlier reported associations with lower wealth $[11,15,16]$. Similarly, no variable measuring wealth or poverty showed to be associated with adolescent pregnancy. However, few present adults might point to inadequate supervision of adolescents that may increase the risk of pregnancy.

The occurrence of adolescent pregnancies in the local community as a significant factor points to the influence of contextual values in the community on teenage pregnancies. A similar result was reported from an analysis of the latest Nicaraguan DHS data, where a high proportion of women having a child increased the occurrence of teen births [35].

A study using the 2001 Nicaraguan Demographic and Health Surveillance data concluded that age at sexual debut was the most influential risk factor and that lack of health care contributed to adolescent pregnancies [36]. That report described the Nicaraguan culture surrounding sex and childbearing as influenced by machismo and marital instability, where Nicaraguan men sought to prove their masculinity by fathering numerous children. Despite this, young women tried to cement their union by having a child. This culture was reportedly the background to the persistently high rate of adolescent pregnancies in the country [36]. A recent study from a context similar to the Cuatro Santos area showed that young girls had less knowledge of sexual and reproductive health, compared to young men and older adolescents [37].

We found an increasing trend in teenage pregnancies over 2009-2014 in our study population. Despite our trend results were not in line to national figures [20], in other LMIC, increasing trends have been experienced in underserved population groups [38-40]. Therefore, our findings support the interest in monitoring adolescent pregnancy in disaggregated subgroups (e.g., geographic and social stratifiers) within the country since subnational-specific health risks seem to vary from incountry targets [41].

The health and demographic surveillance data have shown to be of high quality [24, 25], and cover the whole population in the Cuatro Santos area with very few non-participants. Data on pregnancies in the 10-14-years group are not reliable since the questions in the NN-HDSS questionnaires focused on pregnancies from 15 years of age. Surveys on birth and pregnancy history might be subject to recall bias. To address this bias, we analyzed data from the survey in the three preceding years which is a time used in similar surveys with good quality fertility estimations in low- and middle- income countries [42]. Furthermore, we do not have data on proximal predictors, such as access to reproductive health services, including effective contraception and activities related to sexual violence, gender norms, or status of motherhood as a cultural value. Finally, the CI decision-tree enabled us to simultaneously include and assess the importance of 
a relatively large set of predictor variables with the outcome of adolescent pregnancy. This method also automatically includes and evaluates interactions between the predictors. The output from a CI tree analysis displays precise information about the direction, size, and priority order of the found associations.

\section{Conclusion}

A high incidence of adolescent pregnancies was present in the Cuatro Santos area. There was a steep decline from 2001 to 2007 that was reversed the following years up to 2014. Low education, a high number of working adults in the household, and a high proportion of adolescent pregnancies in the home community were associated with adolescent pregnancies. Household assets reflecting wealth, poverty, or participating in interventions were not linked to teenage pregnancies.

The importance of the level of adolescent pregnancies in the local community indicate that solutions also need to be sought in the context influencing the culture of early motherhood.

\section{Abbreviations}

ABR: Adolescent birth rate; APR: Adolescent pregnancy rates; GDP: Gross domestic product; CIT: Conditional Inference Trees; NN-HDSS: Northern Nicaragua Health and Demographic Surveillance System; SD: Standard Deviation; SDG: Sustainable Development Goals; UBN: Unsatisfied Basic Need Index.

\section{Supplementary Information}

The online version contains supplementary material available at https://doi. org/10.1186/s12884-021-04215-4.

Additional file 1: Figure S1. Cross-validated conditional inference tree, where each end node includes at least 50 individuals. Black areas in end nodes show proportions of 20-24-years-old women stayers (presumed to have stayed in the household they belonged to when getting pregnant or at an earlier age) who experienced adolescent pregnancies (incl. ongoing pregnancies, stillbirths, and abortions) and grey areas women 20-24-yearsold that have not experienced any adolescent pregnancy. The unit of analysis is the individual, but individual variables included were merged with variables at the household and community level referred to each individual using housing ID. AP = Adolescent pregnancy.

Additional file 2: Figure S2. Cross-validated conditional inference tree, where each end node includes at least 50 individuals. Black areas in end nodes show proportions of 20-24-year-old women classified as leavers who experienced adolescent pregnancies (incl. ongoing pregnancies, stillbirths, and abortions) and grey areas women 20-24-year-old classified as leavers that have not experienced any adolescent pregnancy. The unit of analysis is the individual, but individual variables included were merged with variables at the household and community level referred to each individual using housing ID. AP = Adolescent pregnancy.

\section{Acknowledgments}

We acknowledge the Swedish Research Council for funding the research program "Moving evidence-based public health beyond randomized trials: Data Mining strategies to explore contextual influences and predict child mortality outcomes of interventions" (project 2014-2161).

\section{Authors' contributions}

WP and CK conceptualized the paper. CK and KS managed the data, conducted the CIT statistical analyses and drafted the manuscript. WP managed data and conducted the ABR, APR and incidence calculations. OS supported the statistical analyses. EB, MC, CK, RP, WP, and LÅP initiated and worked with the Cuatro Santos HDSS. All authors contributed to and approved the final manuscript

\section{Funding}

Uppsala University, Sweden, supported the Northern Nicaragua Health and Demographic Surveillance System in Cuatro Santos, in collaboration with Centro de Investigación en Demografía y Salud (CIDS), Universidad Nacional Autónoma de Nicaragua (UNAN)-León, Asociación para el Desarrollo Económico y Sostenible de El Espino (APRODESE), and Fundacion Coordinación de Hermanamientos e Iniciativas de Cooperación. The Swedish Research Council funded the present research study (project 2014-2161). The funding agencies had neither any role in the design and conduct of the study, nor in the collection, analysis, and interpretation of the data, nor in the preparation, review, or approval of the manuscript. Open access funding provided by Uppsala University.

\section{Availability of data and materials}

The raw data supporting the conclusions of this manuscript will be made available without undue reservation, to any qualified researcher from the corresponding author on reasonable request (wperezc2018@gmail.com).

\section{Declarations}

Ethics approval and consent to participate

The information was collected as part of the Northern Nicaragua Health and Demographic Surveillance (NN-HDSS) update survey in 2014. All procedures during the design, fieldwork, data management, and analysis of the NN-HDSS -and for the present study- were guided following the ethical principles of the Declaration of Helsinki concerning epidemiological research involving human subjects. The Ethical Review Board of Biomedical Research at the National Autonomous University of León approved the NN-HDSS data collection (León 06 April, 2011. FWA00004523/IRB0000334 ACTA No. 81). Informed consent was obtained from participants and parents or caregivers from participants under 18 years of age. They were free to end their participation at any time. Data were stored in a safe electronic platform with an alphanumeric identification number instead of names of participants to protect confidentiality.

\section{Consent for publication \\ Not applicable.}

\section{Competing interests}

The authors declare that they have no competing interests.

\section{Author details}

'Department of Women's and Children's Health, Uppsala University, Uppsala, Sweden. ${ }^{2}$ Institute of Nutrition of Central America and Panama (INCAP), Calzada Roosevelt 6-25, Zona 11, Guatemala, Guatemala. ${ }^{3}$ Asociación para el Desarrollo Económico y Sostenible de El Espino (APRODESE), Chinandega, Nicaragua. ${ }^{4}$ Nicaraguan Autonomous National University, León (UNAN-León), León, Nicaragua. ${ }^{5}$ Pan American Health Organization, Tegucigalpa, Honduras. ${ }^{6}$ Department of Disease Control, London School of Hygiene \& Tropical Medicine, London, UK. ${ }^{7}$ Department of Computer and Information Science, Linköping University, Linköping, Sweden. ${ }^{8}$ Department of Dental Research, Public Dental Service, Region Örebro County, Faculty of Medicine and Health, Örebro University, Örebro, Sweden.

Received: 14 April 2021 Accepted: 15 October 2021

Published online: 05 November 2021 


\section{References}

1. Berthelon M, Kruger DI. Does adolescent motherhood affect education and labor market outcomes of mothers? A study on young adult women in Chile during 1990-2013. Int J Public Health. 2017;62:293-303.

2. Brosens I, Muter J, Gargett CE, Puttemans P, Benagiano G, Brosens JJ. The impact of uterine immaturity on obstetrical syndromes during adolescence. Am J Obstet Gynecol. 2017:217:546-55.

3. Olausson PO, Cnattingius S, Haglund B. Teenage pregnancies and risk of late fetal death and infant mortality. Br J Obs Gynaecol. 1999:106:116-21.

4. Fall CHD, Sachdev HS, Osmond C, Restrepo-Mendez MC, Victora C, Martorell R, et al. Association between maternal age at childbirth and child and adult outcomes in the offspring: a prospective study in five low-income and middle-income countries (COHORTS collaboration). Lancet Glob Health. 2015;3:e366-77.

5. Patton GC, Coffey C, Sawyer SM, Viner RM, Haller DM, Bose K, et al. Global patterns of mortality in young people: a systematic analysis of population health data. Lancet. 2009;374:881-92.

6. UN. Resolution adopted by the General Assembly on 25 September 2015 Transforming our world: the 2030 Agenda for Sustainable Development. 2015. https://sustainabledevelopment.un.org/post2015/transformingour world. Accessed 21 Oct 2015.

7. UN. Global strategy for women's, children's and adolescents health 20162030: UN; 2021. http://www.who.int/life-course/publications/global-strat egy-2016-2030/en/. Accessed 10 Mar 2021

8. UNFPA. Adolescent pregnancy: a review of the evidence. 2013. https:// www.unfpa.org/publications/adolescent-pregnancy. Accessed $21 \mathrm{Oct}$ 2015

9. WHO. World Health Statistics 2018. Monitoring health for the SDGs, sustainable developement goals. 2018. https://apps.who.int/iris/bitstream/ handle/10665/272596/9789241565585-eng.pdf?ua=. Accessed 15 May 2018

10. Santelli JS, Song X, Garbers S, Sharma V, Viner RM. Global trends in adolescent fertility, 1990-2012, in relation to national wealth, income inequalities, and educational expenditures. J Adolesc Heath. 2017;60:161-8.

11. Caffe S, Plesons M, Camacho AV, Brumana L, Abdool SN, Huaynoca S, et al. Looking back and moving forward: can we accelerate progress on adolescent pregnancy in the Americas? Reprod Health. 2017;14:83.

12. Neal S, Harvey C, Chandra-Mouli V, Caffe S, Camacho AV. Trends in adolescent first births in five countries in Latin America and the Caribbean: disaggregated data from demographic and health surveys. Reprod Health. 2018;15:146.

13. UNFPA. State of world population. The power of choice: reproductive rights and the demographic transition. 2018. https://www.unfpa.org/ sites/default/files/pub-pdf/UNFPA_PUB_2018_EN_SWP.pdf. Accessed 21 Oct 2018

14. Pradhan R, Wynter K, Fisher J. Factors associated with pregnancy among adolescents in low-income and lower middle-income countries: a systematic review. J Epidemiol Community Health. 2015;69:918-24.

15. Govender D, Naidoo S, Taylor M. Scoping review of risk factors of and interventions for adolescent repeat pregnancies: a public health perspective. Afr J Prim Health Care Fam Med. 2018;10(1):1-0.

16. Coyne CA, D'Onofrio BM. Some (but not much) Progress toward understanding teenage childbearing. Adv Child Dev Behav. 2012:42:113-52.

17. Magadi MA. Multilevel determinants of teenage childbearing in subSaharan Africa in the context of HIV/AIDS. Health Place. 2017:46:37-48.

18. Global Planned Parenthood. Stolen lives. A multi-country study on the health effects of forced motherhood on girls 9-14 years old. 2016. https:// www.plannedparenthoodaction.org/uploads/filer_public/db/6d/db6d5 6cb-e854-44bb-9ab7-15bb7fc147c5/ppfa-stolen-lives-english.pdf. Accessed 15 Mar 2016.

19. COMISCA. Plan Estratégico Regional para la Prevención de Embarazo en Adolescentes de Centroamérica y República Dominicana 2019-2023. 2018. https://www.sica.int/documentos/plan-estrategico-para-la-preve ncion-del-embarazo-en-adolescentes-de-centroamerica-y-republicadominicana-2019-2023_1_120456.html. Accessed 12 Mar 2021.

20. PAHO. Core indicators 2019: health trends in the Americas. 2019. https:// iris.paho.org/bitstream/handle/10665.2/51542/9789275121290_eng.pdf? sequence $=6 \&$ is Allowed=y. Accessed 11 Feb 2021.

21. INDEPTH Network. INDEPTH Network. Better health information for better health policy. http://www.indepth-network.org/. Accessed 19 July 2021
22. Sankoh O, Byass P. The INDEPTH Network: filling vital gaps in global epidemiology. Int J Epidemiol. 2012;41:579-88.

23. Gustafsson C. For a better life...A study on migration and health in Nicaragua. 2014. http://umu.diva-portal.org/smash/record.jsf?pid=diva2\% 3A773256\&dswid=7205. Accessed 11 Feb 2021.

24. Blandón EZ, Källestål C, Peña R, Perez W, Berglund S, Contreras M, et al. Breaking the cycles of poverty: strategies, achievements, and lessons learned in Los Cuatro Santos, Nicaragua, 1990-2014. Glob Health Action. 2017;10(1):1272884

25. Pérez W, Blandón E, Persson L-Å, Peña R, Källestål C. Progress towards millennium development goal 1 in northern rural Nicaragua: findings from a health and demographic surveillance site. Int J Equity Health. 2012;11:43.

26. Pérez W, Eriksson L, Blandón EZ, Persson L-Å, Källestål C, Peña R. Comparing progress toward the millennium development goal for under-five mortality in León and Cuatro Santos, Nicaragua, 1990-2008. BMC Pediatr. 2014;14:9.

27. Hammill M. Income poverty and unsatisfied basic needs; 2009. p. 62. https://www.cepal.org/en/publications/25900-income-poverty-andunsatisfied-basic-needs. Accessed 10 Mar 2021.

28. Ballard T, Kepple A, Cafiero C. The food insecurity experience scale: development of a global standard for monitoring hunger worldwide. 2013. http://www.fao.org/fileadmin/templates/ess/voh/FIES_Technical_Paper_ v1.1.pdf. Accessed 12 Mar 2021

29. Hothorn T, Hornik K, Zeileis A. Unbiased recursive partitioning: a conditional inference framework. J Comput Graph Stat. 2006;15:651-74.

30. Hothorn T, Hornik K, Zeileis A. ctree: conditional inference trees: The Comprehensive R Archive Network; 2015. https://rdrr.io/rforge/partykit/f/ inst/doc/ctree.pdf. Accessed 10 Mar 2021.

31. Hastie T, Friedman J, Tibshirani R. The elements of statistical learning. New York: Springer Publishing Company; 2001.

32. R Core Team. R: a language and environment for statistical computing. R Foundation for Statistical Computing. https://www.r-project.org/. Accessed 5 Oct 2018

33. Zeileis A, Hothorn T, Hornik K. party: a laboratory for recursive partytioning. https://cran.r-project.org/web/packages/party/index.html. Accessed 12 Mar 2021.

34. Samandari G, Speizer IS. Adolescent sexual behavior and reproductive outcomes in Central America: trends over the past two decades. Int Perspect Sex Reprod Health. 2010;36:26-35.

35. Mendez Rojas B, Beogo I, Owili PO, Adesanya O, Chen C-Y. Community social capital on the timing of sexual debut and teen birth in Nicaragua: a multilevel approach. BMC Public Health. 2016:16:991.

36. Lion KC, Prata N, Stewart C. Adolescent childbearing in Nicaragua: a quantitative assessment of associated factors. Int Perspect Sex Reprod Health. 2009;35:91-6.

37. Bergström AS, Guevara WJU, Colombo PE, Källestal C. Knowledge about sexual and reproductive health among school enrolled adolescents in Tololar, Nicaragua, a cross-sectional study. J Public Health Int. 2018;1:27-38.

38. Chirwa GC, Mazalale J, Likupe G, Nkhoma D, Chiwaula L, Chintsanya J. An evolution of socioeconomic related inequality in teenage pregnancy and childbearing in Malawi. PLoS One. 2019;14(11):e0225374.

39. Buratto J, Kretzer MR, Freias PF, Traebert J, Nunes RD. Temporal trend of adolescent pregnancy in Brasil. Rev Assoc Med Bras. 2019;65(6):880-5.

40. Kassa GM, Arowojolu AO, Odukogbe ATA, Yalew AW. Trends and determinants of teenage childbearing in Ethiopia: evidence from the 2000 to 2016 demographic and health surveys; 2019. https://doi.org/10.1186/ s13052-019-0745-4.

41. Huda MM, O'Flaherty M, Finlay JE, Al Mamun A. Time trends and sociodemographic inequalities in the prevalence of adolescent motherhood in 74 low-income and middle-income countries: a population-based study. Lancet Child Adolesc Heal. 2021:5:26-36.

42. USAID. Quality and consistency of DHS fertility estimates, 1990 to 2012: DHS methodological reports no. 12. 2014. https://dhsprogram.com/ pubs/pdf/MR12/MR12.pdf. Accessed 15 July 2021.

\section{Publisher's Note}

Springer Nature remains neutral with regard to jurisdictional claims in published maps and institutional affiliations. 